\title{
41 Year-Old Male Dies after Being Struck in the Head with an Auger
}

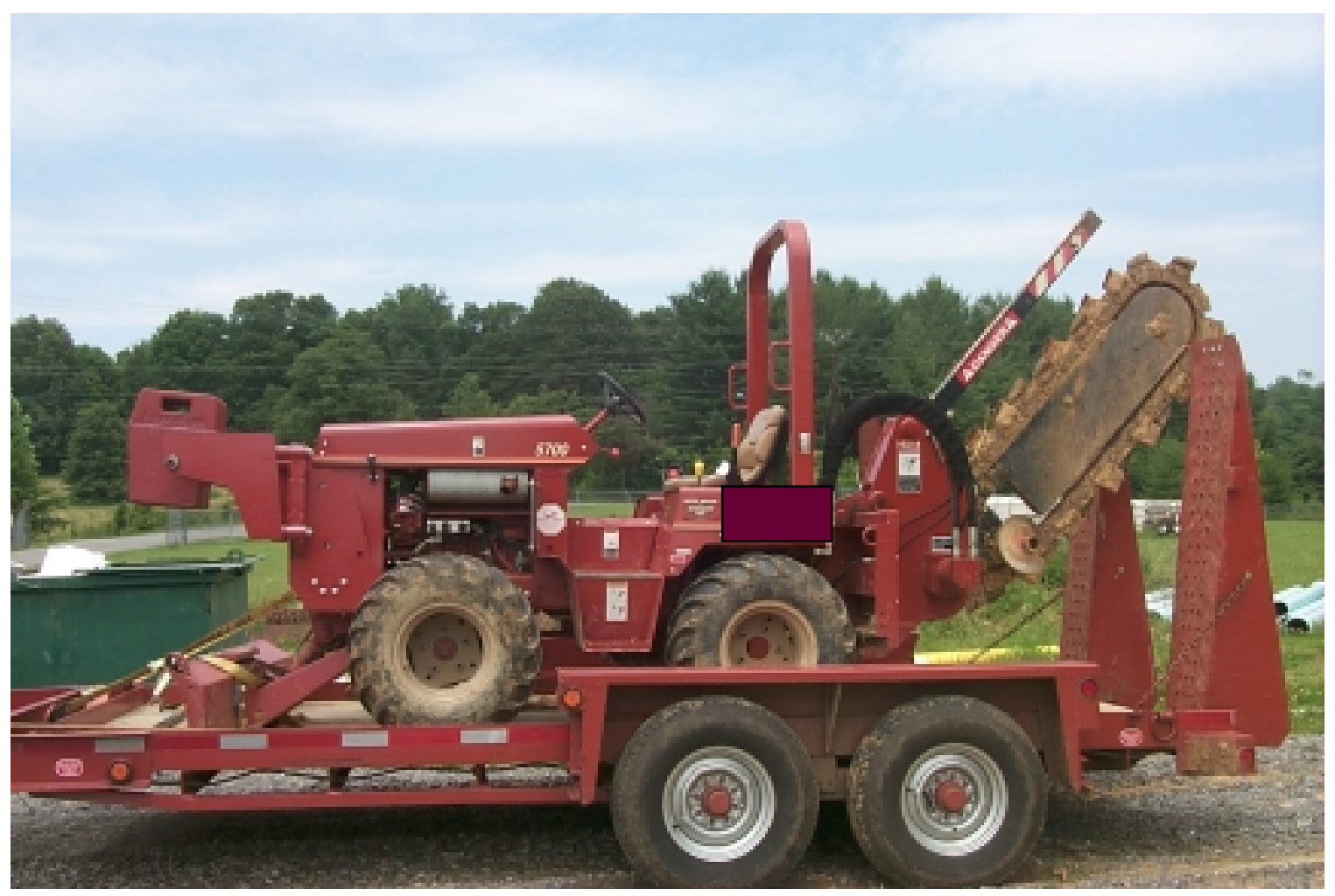

\section{Incident Number: $\quad$ 02KY127 \\ Date of Incident: $\quad$ October 23, 2002 \\ Report Release Date: June 17, 2003}

Kentucky Fatality Assessment and Control Evaluation Progran Kentucky Injury Prevention and Research Center 333 Waller Avenue

Suite 202

Lexington, Kentucky 40504

Phone: 859-323-2981

Fax: 859-257-3909

www.kiprc.uky.edu

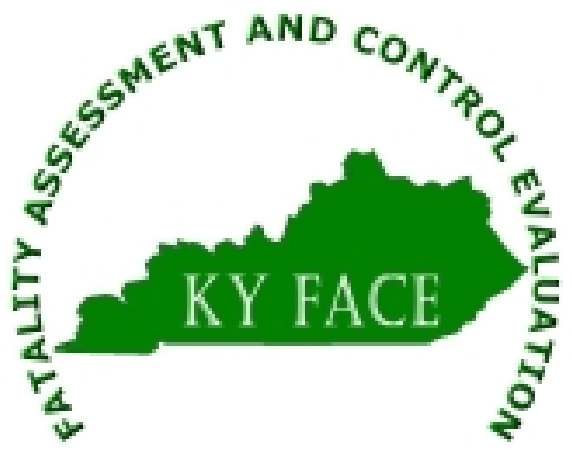


Kentucky Fatality Assessment \& Control Evaluation (FACE) Program

Incident: 02KY127

Release Date: June 17, 2003

Subject: 41 Year-Old Male Dies after Being Struck in the Head with an Auger

\section{Summary}

On October 23, 2002, a 41 year-old male (decedent) died after he was hit in the head with the handle of an auger. He was part of a four-member work crew tying water lines of private residences into a municipal water line. He was injured while backing the auger out of the hole and the handle became tangled with the rotating auger bit which caused the handle to flip up and strike him in the head, twice. After being struck, with co-workers following him trying to convince him to sit down, he walked away from the site until emergency rescue workers arrived and convinced him to sit down on a stretcher. He was transported to a local hospital then air lifted to a larger facility where he died five days later from a closed head injury.

To prevent similar incidents from occurring, KY FACE recommends:

- Employees should practice safe operating procedures when using dangerous equipment.

- Equipment manufacturers should re-evaluate the design of the handle to direct auger bits and research the possibility of a new design.

\section{Introduction and Background}

A Kentucky state agency notified the FACE program on January 27, 2003, of an incident involving a 41 year-old male and an auger. On February 21, 2003, KY FACE had an interview with the director of a municipal water department regarding the incident. An officer of the Kentucky Occupational Safety and Health was also interviewed. The water plant had been in operation since 1963 and employed nine persons. The decedent had worked for the municipality for a little over a year. Soon after his employment, the municipality bought a new auger to bore holes. With the purchase, the manufacturer provided training on the auger for all employees including the decedent. After being trained, the decedent bored hundreds of holes with the new auger. The decedent had also read the safety policy manual required by the municipality. Toolbox talks were routinely held and safety training was held annually.

The auger was powered by a tractor like device. It requires an operator in the cab controlling the off / on switch and an operator on the ground guiding the auger bit. When the auger is moving forward, away from the operator, it can be guided by a handle. If the direction of the auger bit needs to be reversed, the handle must be removed before it begins reverse direction.

\section{Investigation}

On October 23, 2002, four workers were installing water lines in a new housing development. The main water line ran alongside a two-lane residential street. To tie the water lines from the houses into the main water line, the work crew had to bore holes under the street. 
Around noon, the crew was in the process of installing a water line from a house to the water main. They were trying to bore under the street. The machine driving the auger bit was parked at the corner of the house. A ditch approximately 15 feet long, 20 inches deep and six inches wide had been made from the machine to the street. It was a routine job until the crew tried to bore under the two lane street. The first attempt had to be aborted because the operator guiding the auger bit hit rock. A second attempt was made approximately six to eight feet to the right of the first boring attempt. The cab operator saw the auger operator (decedent) hit rock again and began to reverse the direction of the auger bit. At the same time the auger operator hit rock and reversed the bit, he looked over his shoulder as if distracted by something behind him. The bit became entangled in the end of the handle, causing it to fly up and hit the auger operator in the head twice. The operator walked away from the scene with his crew mates trying to get him to sit down. A crew member radioed the supervisor at the water treatment plant office who called emergency medical services. Emergency services arrived about 10 minutes later, and carried a stretcher to where the operator was walking. They were able to convince the operator to sit on the stretcher. He was then tied to the stretcher and transported to a nearby hospital. From there he was later airlifted to a trauma center where he died 5 days later from a closed head injury.

After the incident, new safety procedures to be followed before operating jobsite equipment were written and distributed to the employees. The new procedures address proper training on equipment, jobsite hazard assessment, wearing personal protective equipment and safe drilling practices.

\section{Cause of Death}

The Death Certificate listed the cause of death as "closed head injury from an industrial accident".

\section{Recommendations and Discussion}

1. Employees should practice established safe operating procedures when using dangerous equipment.

There are four components to the auger: the power train, the rod, the handle and the bit. The bit is attached to the end of the rod, which is guided on the side by the handle. The handle has two open loops that are open on opposite sides of the loop. These loops fit over the rod. The power train makes the rod and bit rotate to move forward or backward. The handle on the rod allows the operator to guide the bit where it needs to bore. The handle should not touch the bit, only the rod. According to safe operating procedures, when the bit direction is reversed, the handle needs to be removed. This prevents the bit from becoming entangled in the handle. Training should be reinforced on a regular basis on correct use of augers. Had the handle been removed prior to reversing direction, this incident may have been prevented.

2. Equipment manufacturers should re-evaluate the design of the handle to direct auger bits and research the possibility of a new design. 
When an auger is being operated forward, it can be guided by a handle. When the bit direction is reversed, the handle should be removed. This keeps the bit from becoming entangled in the handle. The decedent had safely operated the auger hundreds of times before the incident occurred. It is unknown why he did not remove the handle in this particular instance. Perhaps manufacturers could research different handle designs and attachment mechanisms to allow the handle to stay attached safely while the bit is moving in the reverse direction. Another option would be to have the bit un-operational in the reverse direction when the handle is still attached.

Note: As of the writing of this report, the handle design has been redesigned by the manufacturer to break away if the bit and rod become uncontrollable. The handles are being replaced free of charge to customers.

\section{Key words: \\ auger, \\ bit, \\ ditch, \\ distracted}

The Kentucky Fatality Assessment \& Control Evaluation Program (FACE) is funded by a grant from the Centers for Disease Control and the National Institute of Safety and Health. FACE's purpose is to aid in the research and prevention of occupational fatalities by evaluating events leading to, during, and after a work related fatality. Recommendations are made to aid employers and employees to have a safer work environment. Current focuses of the program are occupational fatalities involving: construction, machinery, immigrant workers (particularly Hispanics) and youth. For more information about FACE and KIPRC, please visit our website at: www.kiprc.uky.edu 


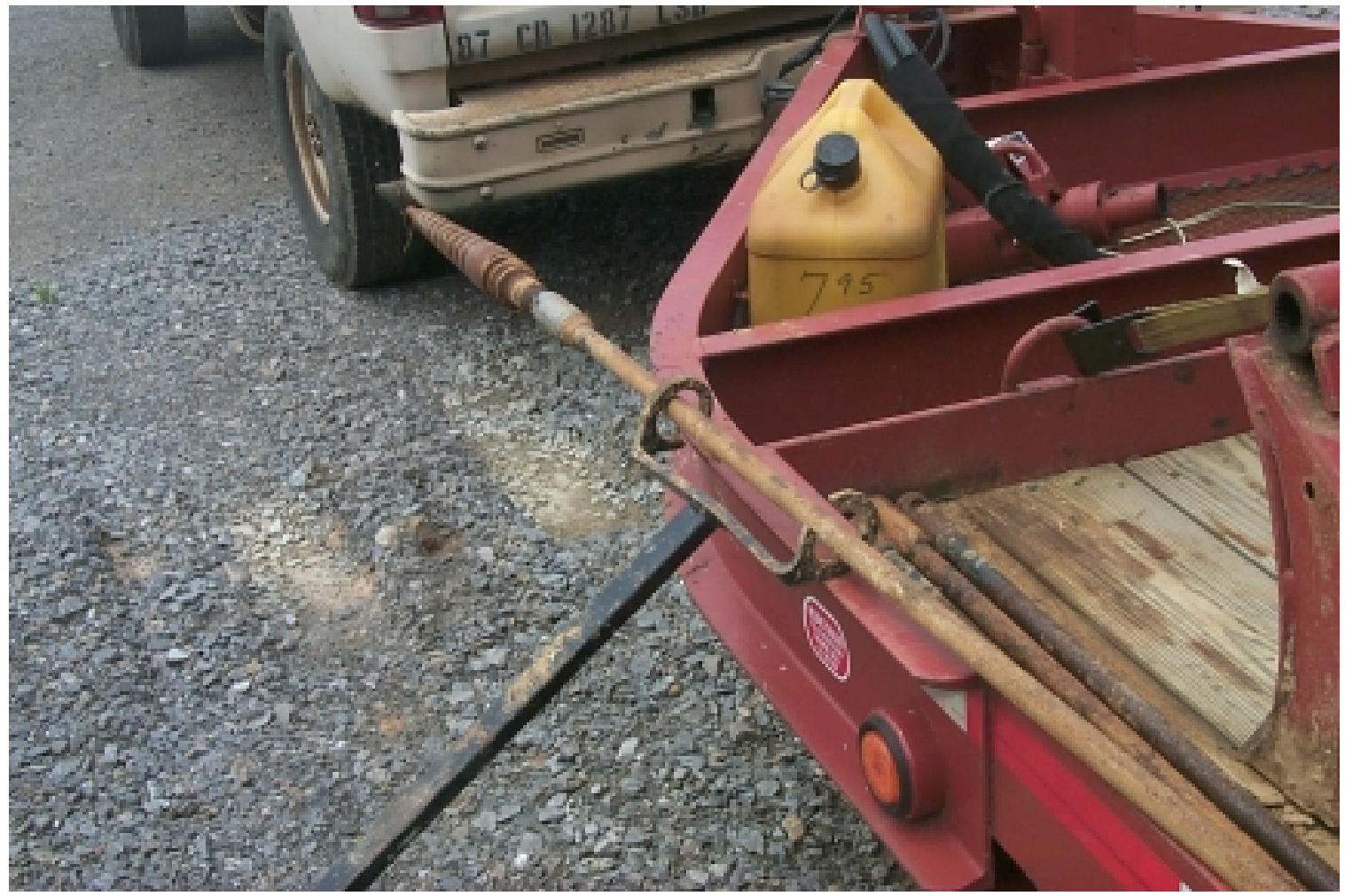

Auger bit with handle in proper location on rod to guide bit forward.

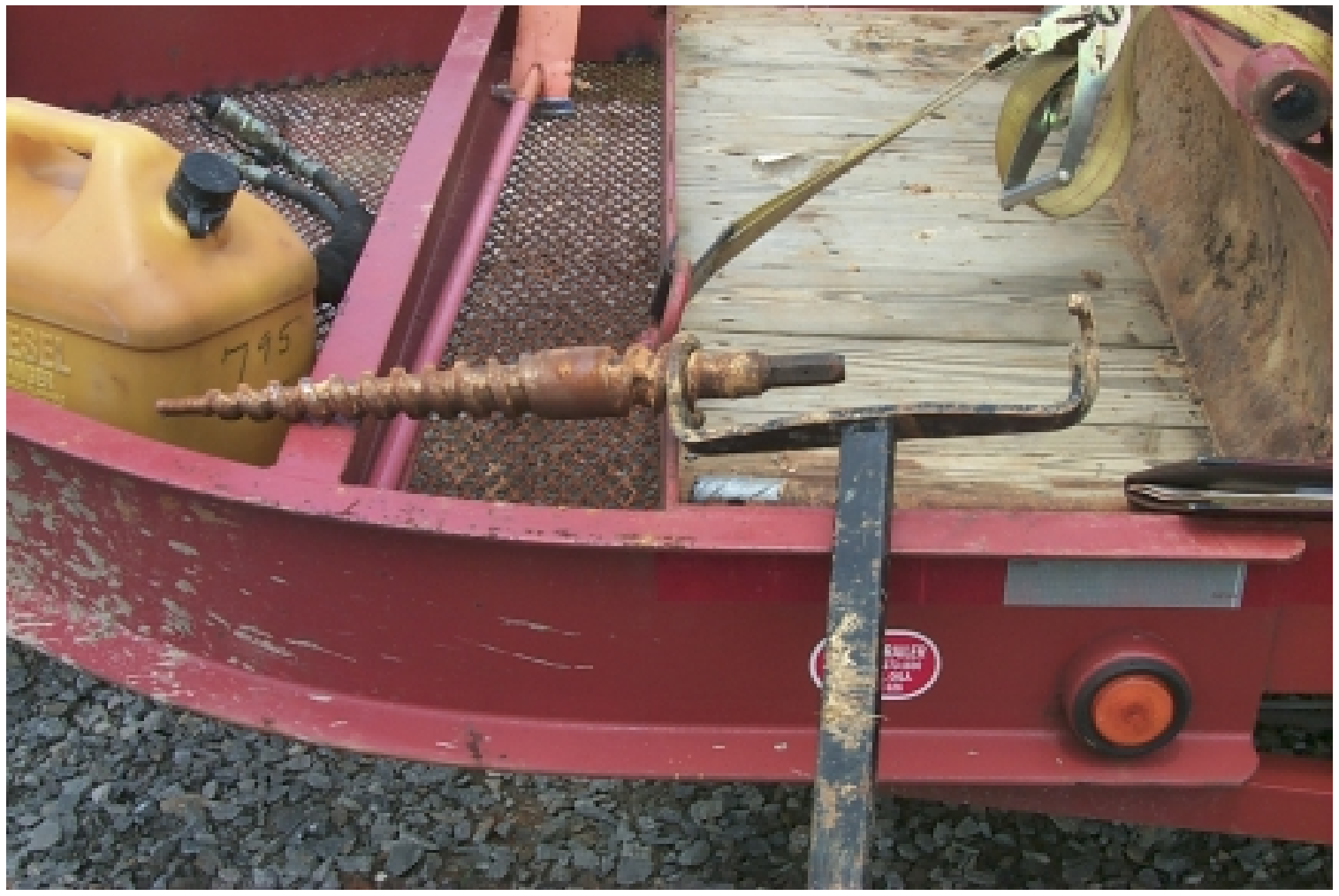

Auger bit threaded into handle as it would have done at time of incident. 